\title{
War Experiences, Posttraumatic Stress Disorder, Sleep Disorders: Clinical Effectiveness of Treatment by Repeating Phrases of Positive Thoughts (TRPPT) of Mental-War Disorders in Syrian Refugees Children and Adolescents War Victims - A New Therapeutic Trial
}

\author{
Amani Kubitary ${ }^{1}$, Muaweah Ahmad Alsaleh²
}

${ }^{1}$ PhD Student in Mental Health, Psychologist-Ibn Sina Hospital for Mental Disorders, Laboratory of Mental Health, Faculty of Education, University of Damascus, Syria

${ }^{2} \mathrm{PhD}$ \& MS in Psychological Studies, neuropsychologist, psychotherapist, psychology researcher, behavioural science, practice of psychotherapy and clinical psychopathology, health ethics, method in psychology statistics, Center for Research on Risks and Vulnerabilities (CERReV) - University of Caen Normandy, \& Health faculty, France; and Faculty of Education - Counseling psychology - University of Aleppo, Syria

Background: War contributes to sleep disorders and posttraumatic stress disorder by war experiences. Theses mental and psychological troubles are a common symptom in children and adolescents during Wartime.

Aim: The objective of this study was the first to evaluate the effects of the method of Therapy by Repeating Phrases of Positive Thoughts (TRPPT) and Cognitive and Positive psychotherapy (CPPT) training during Wartime among children and adolescents in Syria. This study attempted to treat the evils of wars, which cause deep wounds and psychological scares because of their horrors. Method: The sample consisted of 41 Syrian children and adolescents, aged 13 to 17 years.

Results: 41 Syrian children and adolescents (experimental group) who benefited from TRPPT have the decreasingon Posttraumatic stress disorder (PTSD), Sleep Disorders (SD) and remember of War Experiences (WE). The results showed a significant decrease in PTSD in throughout the Therapy $(p<0.05)$ and a significant reduction in SD following the TRPPT protocol $(p<0.001)$, and also less Negative War Experiences $(p<0.01)$.

Conclusions: States of mind and psychologic were improved after the TRPPT. Treatment by repeating phrases positive thoughts will be significant among children and adolescents refugees subjected to war or no. Cognitive and positive psychotherapy based on TRPPT have an impact positive on evils of wars, which cause Posttraumatic stress disorder, Sleep Disorders and Negatives War Experiences. There is a dose effect: the higher the level of activity of the CPPT and TRPPT, the lower the psychiatric disorder, and the better of the health.

Keywords: wartime, peacetime, behavioral and cognitive psychotherapy, cognitive psychology, mindfulness-based cognitive therapy, positive psychology, research, practice, cognitive activity, Syria
\end{abstract}

\section{*Correspondence: moaouiya87@yahoo.com}

Muaweah Ahmad Alsaleh, PhD \& MS-Neuropsychologie Cognitive and Social, Psychotherapy, Health Ethics, Biostatistics, Center for Research on Risks and Vulnerabilities (CERReV) at the University of Caen Normandy \& Health faculty, France; and Faculty of Education - Counseling psychology -University of Aleppo, Syria, Phone: +33 786569245

Received: 10 July 2017 Accepted: 27 October 2017

\section{Sleep and Hypnosis}

Journal homepage: 


\section{INTRODUCTION}

Mental disorders among people in War conditions are very frequent (see Alsaleh, 2016a; Alsaleh\&Kubitary, 2016a, 2016b, 2016c; Kubitary, Alomer, \&Alsaleh, 2017; Kubitary\&Alsaleh, 2017; Alsaleh\&Kubitary, 2017). Depression and posttraumatic stress disorder (PTSD) are the most common mental health problems among Syrian refugees (Dhamrah\&Abueita, 2014; Acarturk, Konuk, Cetinkaya, Senay, Sijbrandij, Cuijpers, \& Aker, 2015; ALShagran, Khasawneh, Ahmed, \& Jarrah, 2015; Sirin\& Rogers-Sirin, 2015). More than 2,846,186 are displaced Syrian people worldwide (UNHCR, 2013a). More than 13 million are internally displaced people in the Syrian interior.

Refugees and displaced people are forced to leave their home countries (UNHCR, 2004, see Acarturk et al., 2015), their home, their memories, their place of birth, and their affiliation because of war.

Syria is currently in the midst of a crisis level complex emergency, which started in 2011. United Nations High Commission for Refugees (UNHCR), United Nations (UN) and Government of Syria joint assessment mission highlighted mental health and psychosocial support (MHPSS) as one of the most urgent concerns resulting from the crisis (Acarturk et al., 2015; Alsaleh, 2016a; Alsaleh \& Kubitary, 2016a, 2016b, 2016c, Kubitary et al., 2017; Kubitary \& Alsaleh, 2017). "According to Human Care Syria, there are about 2.4 million refugees living in dire condition. Out of these refugees about 534,418 are now living in Jordan. About $50 \%$ of them are children. As a result of these parents also suffered the same fate as well." (ALShagranet al., 2015). One of the priorities and the challenge during wartime is to protect and improve people's mental health and psychosocial well-being, especially the children and adolescents.

Almost 12 million children have been displaced or have lost one of their parents as a result of armed conflicts around the world (Papageorgiou, Frangou-Garunovic, lordanidou, Yule, Smith, \& Vostanis, 2000; Damra\&Nassar,
2014). Psychological trauma of various kinds may affect the lives of $25 \%$ children around the world (Ammar, 2006; see Damra\&Nassar, 2014). Traumas impact on the children and adults (AL-Balhan,2006; Berthold,2000; Damra\&Nassar, 2014).There is a belief that the exposure of children and adolescents to wars will lead to long-term psychological effects (Vernberg, 2002; Dhamrah\&Abueita, 2014) which will affect their future lives (Brown, Pearlman, \& Goodman, 2004; Damra \& Nassar, 2014). Syrian children and adolescent living in a Turkish refugee camp are at risk for a range of mental health issues resulting from their War experiences as Posttraumatic stress disorder which is the most common problem followed by depression (Thabet, Abed, \&Vostanis, 2004; Henley \& Robinson, 2011; Dhamrah\&Abueita, 2014; Hasanovic, 2012; Sirin\& Rogers-Sirin, 2015).PTSD is the most common psychological symptom among War Children (Dhamrah\&Abueita, 2014). Effect of war on children and adolescents are sure with PTSD as a main war trauma outcome (Baddoura\&Merhi, 2015).

"Syrian refugees are in desperate need for serious psychological help and support to overcome their traumatic horror they have been through and still persist" (ALShagran et al., 2015). "Standardized $C B T^{*}$ and EMDR interventions can significantly improve functioning of disaster-exposed children" (de Roos, Greenwald, den Hollander-Gijsman, Noorthoorn, van Buuren, \&de Jongh, 2011)."EMDR therapy shows promise as an effective treatment for depressive disorders" (Hase, Balmaceda, Hase, Lehnung, Tumani, Huchzermeier, \&Hofmann, 2015). Cognitive Behavior Therapy was used with childhood traumatic grief (CTG) (Brown, Pearlman, \& Goodman, 2004), and with depression (Oras, De Ezpeleta, \&Ahmad, 2004; Cohen, 2005; Damra\&Nassar, 2014). TraumaFocused Cognitive Behavior Therapy (TF- CBT) had the effect on reduction the depression symptomatology in War Children's and PTSD, depressive, and behavioral problems in sexually abused children and adolescents (Cohen\&Mannarino, 1998, 2008; Mohlen, Parzer, Resch, \&Brunner,2005; Cohen, 2005; Raider, Steele, Delillo- 
Storey,Jacobs, \& Kuban, 2008; Eskin, Ertekin,\&Demir,2008; Feather\& Ronan,2009; Damra \& Nassar, 2014; Dhamrah \& Abueita, 2014). Cognitive therapy as Mindfulness-Based Intervention (MBI) had an impact positive in primary education settings as in rural schools (Ricarte, Ros, \&Latorre, 2015). Positive thinking and cognitions are the protective factors and have important effects (see Kirkegaard-Weston, 2005; Zauszniewski, Bekhet, \& Jane Suresky, 2009; Alsaleh, 2016a, 2016b; Alsaleh\&Kubitary, 2016a, 2016b, 2016c; Alsaleh, Lebreuilly, Lebreuilly, \&Tostain, 2017; Alsaleh\&Kubitary, 2017). "By repeating positive self-phrases one is reaffirming positive phrases to oneself everyday" (Kirkegaard-Weston, 2005). The positive phrases motivating individuals have been used with students at university and school(Kirkegaard-Weston, 2005; Alsaleh, 2016a, 2016b)."By repeating these phrases, one gets the child used to saying these phrases, which will encourage the child to say them by him or herself" (Kirkegaard-Weston, 2005). Cognitive and Positive psychotherapy (CPPT) basing on the Treatment by Repeating Phrases of Positive Thoughts (TRPPT) have shown that the TRPPT are efficacious in treating anxious depressive disorders and symptoms in individuals and improve people's mental health and psychosocial wellbeing.These interventions (TRPPT), which suggest activities to cultivate positive emotions, positive behaviors or positive cognitions, are effective in increasing the wellbeing (self-esteem and life satisfaction) and improve symptoms of psychological and psychiatric diseases such as symptoms of depression, anxiety and stress (Alsaleh, 2016a, 2016b; Alsaleh \& Kubitary, 2016a, 2016b, 2016c; Alsaleh et al., 2017). The studies findings on TRPPT indicated the efficacy of the TRPPT on decreasing the negative automatic thought, depression, anxiety, stress, increasing the positive automatic thought, and improving self-esteem and satisfaction with life during Wartime or outside Wartime (Alsaleh, 2016a, 2016b; Alsaleh \& Kubitary, 2016a, 2016b, 2016c; Alsaleh et al., 2017; Alsaleh \& Kubitary, 2017).

People who regularly practice cognitive activity have a greater volume of gray matter (especially at the level of the prefrontal cortex and the hippocampus), and less cerebral atrophy, than those who are not engaged in such activity. Cognitive activities would therefore have a complementary interest in delaying the effects of cerebral aging. The cognitive activity could have a benefit on the plasticity of certain brain regions. Cognitive activity is beneficial at any age. There is a dose effect: the higher the level of activity, the higher the gray matter brain volumes (Koseki, Noda, Yokoyama, Kunisato, Ito, Suyama, Matsuda, Sugimura, Ishihara, Shimizu, Nakazawa, Yoshida, Arima, \&Suzuki, 2013; Arenaza-Urquijo, de Flores, Gonneaud, Wirth, Ourry, Callewaert, Landeau, Egret, Mézenge, Desgranges, \&Chételat, 2016). "Participants with a high frequency of positive automatic thoughts showed lower activation in the right superior temporalgyrus (STG) than did those with a low frequency of positive automatic thoughts, whereas participants with a high frequency of positive automatic thoughts showed higher activation in the left dorsolateral prefrontal cortex (DLPFC) than those with a low frequency of positive automatic thoughts" (Koseki et al., 2013). Right superior temporal gyrus is related to negative emotional processing (Koseki et al., 2013)."The DLPFC is involved in cognitive abilities characterized as executive functions (e.g., working memory and attention capacity) that help maintain goals and predict the future consequences of behavior" (Koseki et al., 2013).

"The onset of these mental health problems can have long-term negative consequences for children"(Sirin\& Rogers-Sirin, 2015). During Wartime, children and adolescents are the most vulnerable groups of society and subjected to physical and psychological abuse (Berthold, 2000; Brown, Pearlman, \& Goodman, 2004; Damra\&Nassar, 2014). Iraqis children, aged 6-18 years, who suffer bombing events and detonation have sleep problems (see Dhamrah\&Abueita, 2014). Sleep deprivation can lead to psychiatric disorders as high anxiety (Goldstein, Greer, Saletin, Harvey, Nitschke, \& Walker, 2013) and affects the ability to choose proper foods (American Academy of Sleep Medicine, 2012). Most studies are carried out on refugees abroad or on the Syrian border (Damra\&Nassar, 2014; Acarturk et al., 2015; AL-Shagranet al., 2015, Sirin\& Rogers-Sirin, 2015), there are no studies in the Syrian interior. During 7 years of wartime, Syrian children and adolescents 
have sleep deprivation and suffer from lack of good and deep sleep, and proper foods. Syrian children and adolescents were exposed direct and indirect War Experiences and Posttraumatic Stress Disorder. The studies of Alsaleh recommended the importance of having more studies for investigating the TRPPT effect on other war mental health aspects (e.g. sleep disorder and posttraumatic stress disorder). Therefore, the aim of this study was to explore the effects of the TRPPT on the Posttraumatic Stress Disorder (PTSD), Sleep Disorder (SD) and War Experiences (WE) during wartime among the children and adolescents in Syria, especially in the Syrian interior.

\section{METHODS}

\section{Participants and inclusion Criteria}

Clinical Study (CS) was conducted on non-clinical sample during Wartime. 41 Syrian boys aged 13 and 17 years of the school in Damascus was comprised. Boys' pupils between thirteen and seventeen years old were included in the study. All pupils were Syrian. This CS was administered on sample considered as a non-sick sample (non-clinical sample).The participants have been sampled randomly.

\section{Confounding factors}

"Failure to evaluate demographic and clinical factors as potential confounders can bias your study results and lead to erroneous conclusions. Study design must include the measurement and reporting of such factors. In all likelihood, no matter how many variables one adjusts for, there will be residual confounding, possibly by factors that are unknown and cannot be measured" (Skelly, Dettori, \& Brodt, 2012). In study which assesses the effectiveness of psychotherapy, confounding factors as gender and/or age differences may influence the psychotherapy of patients as well as their chances of recovery (see Alsaleh, 2016a). Studies confirm that the best results through homogeneity in sex and that there are no differences in other factors such as education and level economic and social (Belhsini, 2011; Alsaleh, 2016a). Therefore, in this study, confounding was accounted during study planning and analysis, according to the recommendation (see Belhsini, 2011; Skelly, Dettori\& Brodt, 2012; Alsaleh, Lebreuilly, Lebreuilly,\&Tostain, 2015;Alsaleh, 2016a). A narrow age range was selected to control its impact on the variables and the results of the study. For gender, in order to avoid if sex has an effect on the TRPPT, the study only takes homogeneous groups, only Boys. To avoid bias of sex and age and the selection of sex and population on the results and to generalize the results and effectiveness of the therapy, the studies of Alsaleh, have tested the effectiveness of the TRPPT on the different sex, different ages, and different population (see Alsaleh, 2016a; 2016b; Alsaleh\&Kubitary, 2016a,Alsaleh et al., 2017).

\section{Human ethics committee}

This study was approved by the director of the school and the staff of the steering and educational in this school. Orally consents were obtained from the participants after the aims and objectives of the study have been explained. All the persons who participated in this study have given the informed consent.

\section{Procedure of the TRPPT}

According to this scheme, the procedure was conducted (see Figure 1).In this study, cognitive and positive training exercises were: observation of the thoughts, stop of negative thoughts, repeat positive words and phrases, replace negative thoughts with positive thoughts (Weeks 1 and 5). Cognitive and positive therapeutic intervention was distributed over the 5 -weeks period.

\section{Techniques and Services of TRPPT: Practical proceedings of study and TRPPT method}

This TRPPT procedure was performed with pupils at school. 17 boys are war victims and refugees in Damascus, and 24 boys are living in Damascus (see Figure 2). Control group was not assigned to a waiting list.

The treatment program includes two active techniques: 1. Repeat only the positive words (words in self-repetition); 2 . Repeat during 5 - weeks (33 days) the three phrases of positive thoughts from 3 to 5 minutes per day. TRPPT includes a training of repetitions phrases 
According to this scheme, the procedure was conducted.

First an interview: school principal and head of studies in school

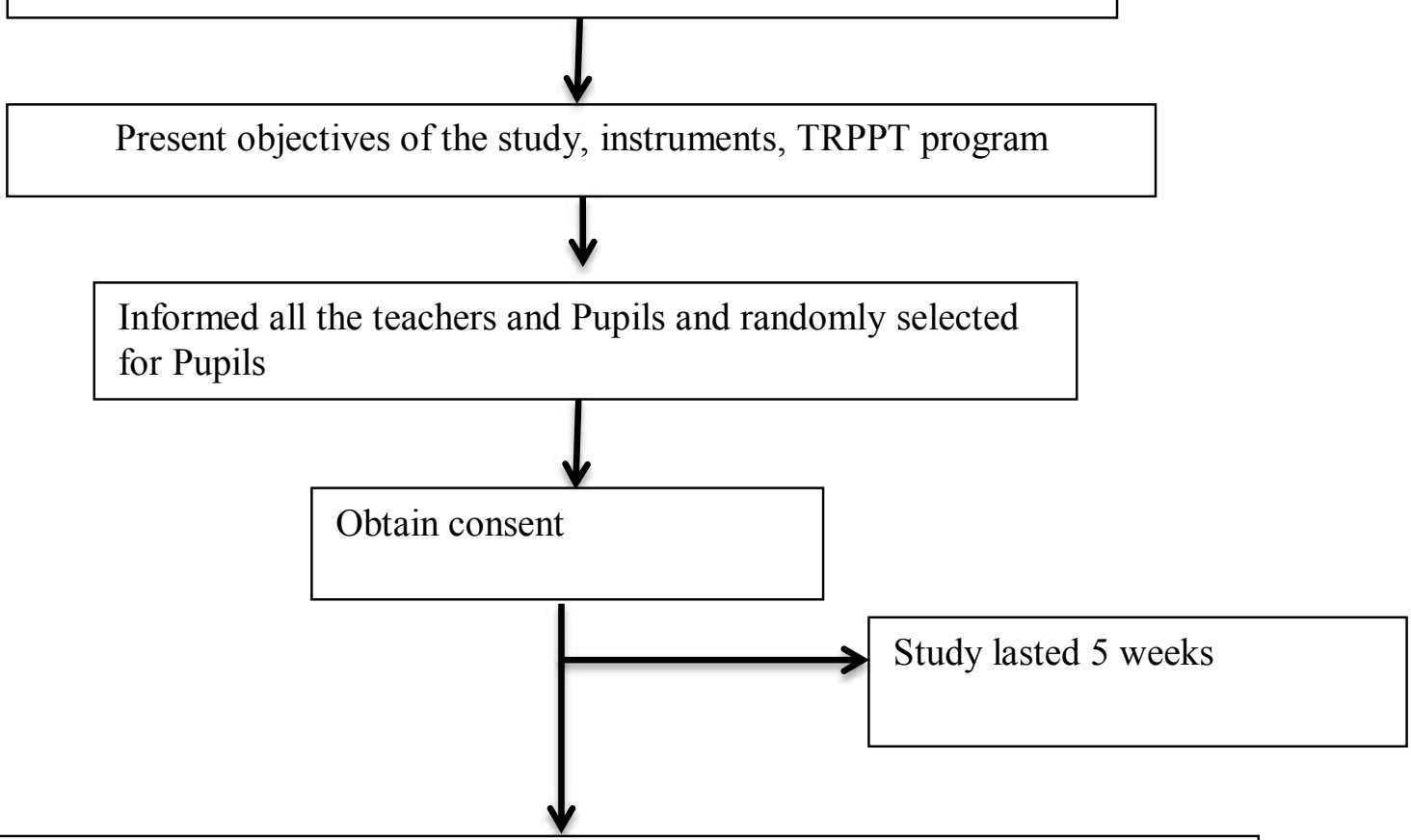

In Week 1:

$1^{\text {st }}$ day: pupils completed the instruments (pre-test of dependent variables) and individually with psychologist.

$2^{\text {nd }}$ day: received education in the RPPT by psychologist.

Week 1 to Week 5:

In the $3^{\text {rd }}$ day to $32^{\text {rd }}$ : TRPPT program was implemented with pupils (experimental group). Activities techniques of RPPT were conducted in the pupils' usual classrooms and only at the home after the school.

Positive words were applied at the same time every day.

New positive words give of pupils each Week at the same time every day in a 10-minute session with 10-minute session of motivation.

In Week 5:

In the $33^{\text {rd }}$ day: pupils completed the instruments (post-test of dependent variables), in the same conditions as at pre-test

Figure 1: Procedure of TRPPT. 
According to this scheme, the data collection process and TRPPT take place in several stages. All participants completed these questionnaires ${ }^{1}$.

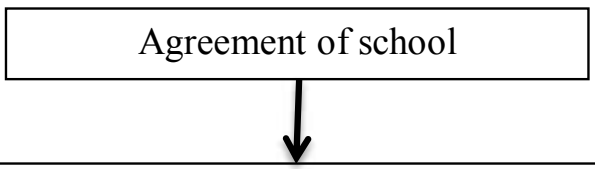

Pupil agreement (44 participants, randomly selected, were assessed for eligibility (T1)

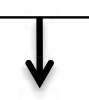

\section{Evaluation scales (T1, initial evaluation after the agreement).}

Syrian sample: 44 Pupils from the school of Damascus:

25 pupils resident originally in Damascus,

19 pupils war victims refugee at Damascus and escaped from their original place of residence to Damascus.

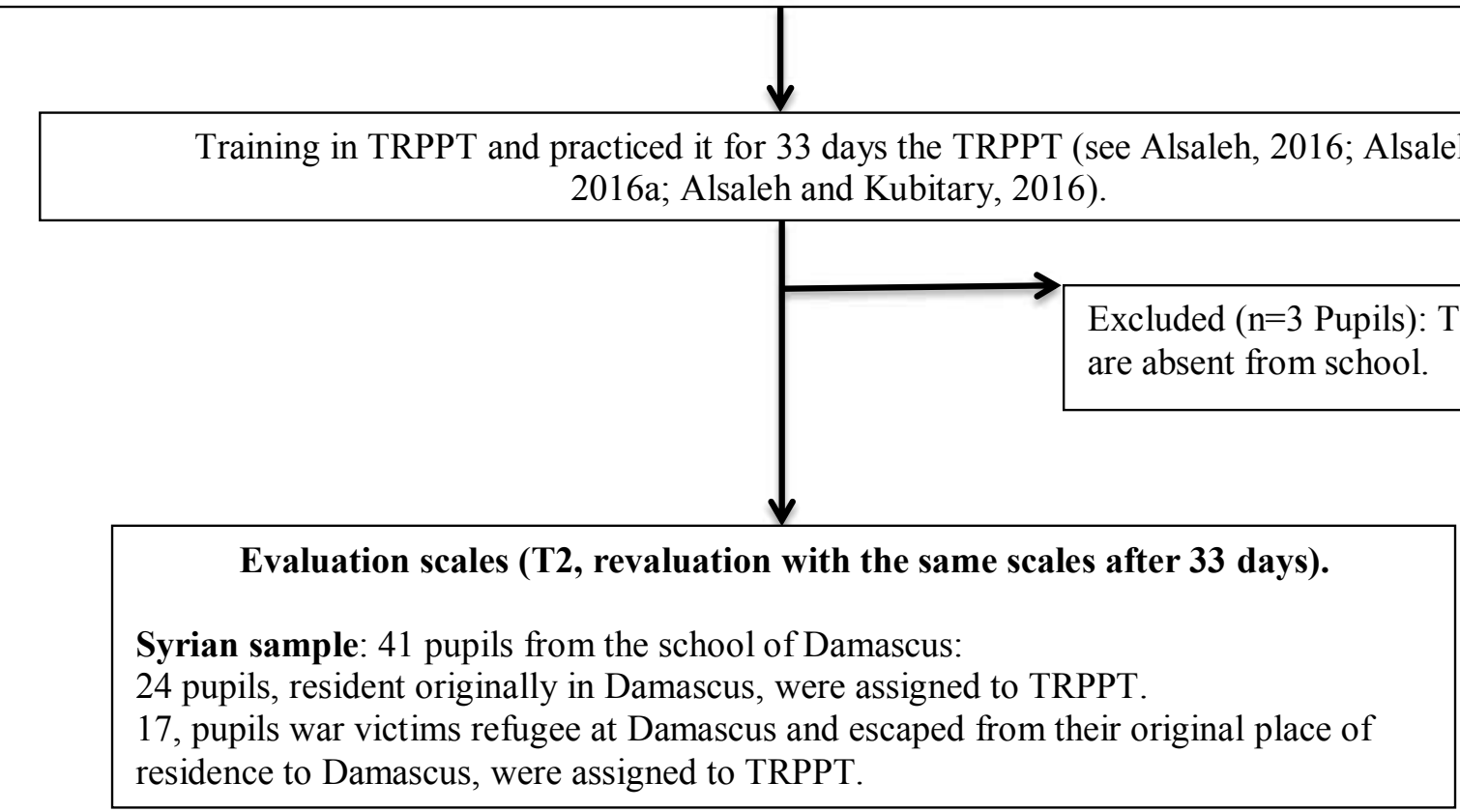

Figure 2: Practical proceedings diagram of TRPPT.

\footnotetext{
${ }^{1}$ For Syrian participants completed:

1. Davidson Trauma Scale (DTS).

2. Kubitary-Alsaleh War Experiences Scale (KAWES).

3. Sleep Disorders Scale (SDS).
} 
with very positive sense. Pupils have received education in the TRPPT for $1 \mathrm{~h} 30$ minutes, led by a psychologist, with an explanation on the progress of research and measurement tools (Alsaleh, 2016a, 2016b; Alsaleh\&Kubitary, 2016a, 2016b, 2016c).

The guidelines should be taught only once in the first training session for about 30 minutes to $1 \mathrm{~h}$ according to age. Thus, the instruction given on the observance of the TRPPT is to repeat the three sentences at least three times, for 3 to $5 \mathrm{~min}$ from the morning awakening, evening before sleeping. It has been teaching kids how to use the TRPPT during the day, before going to the evening, and in family and social relationships. Pupils have received education how to make positive sentences according to the daily situation. In addition, these Phrases of Positive Thoughts (PPT) can be repeated mentally throughout the day during performing daily actions (eating, walking, wait urban transport, ride a bike, before an interview, etc.) (Alsaleh, 2016a,2016b; Alsaleh\&Kubitary, 2016a, 2016b, 2016c). By Repeating Phrases of Positive Thoughts, these phrases penetrate into the usual thinking pattern of internal cognition, which motivate individuals and become a vital aspect of thinking and in the forefront of mind and continually being forced to think about purpose as aim in life (Kirkegaard-Weston, 2005; Alsaleh, 2016a, 2016b; Alsaleh et al., 2017). The guidelines and positive words and phrases of the TRPPT are available at from the first author or corresponding author (Correspondence), and also at the articles of Alsaleh (Alsaleh, 2016b; Alsaleh \& Kubitary, 2016b; Alsaleh \& Kubitary, 2017; Alsaleh et al., 2017). The guidelines and positive words and phrases are available in the Arabic version(Alsaleh \& Kubitary, 2016b; Alsaleh \& Kubitary, 2017), the French version (Alsaleh, 2016b Alsaleh et al., 2017), and the English version (Alsaleh \& Kubitary, 2016b; Alsaleh \& Kubitary, 2017). Other positive words and phrases are only available from the first author or corresponding author.

Unlike drug treatments, TRPPT is no limit to consumption or undesirable side effects (Alsaleh, 2016a, 2016b; Alsaleh et al., 2017). The intervention of the RPPP can organize and target around several axes, physiological (relaxation); Cognitive (identification of cognitive patterns, negative thoughts, erroneous interpretations); Emotional (decreasing depressive feelings and related anxiety and decreasing frequency of anger); and behavioral (improving social skills) (Alsaleh, 2016b; see Alsaleh et al., 2017). Alsaleh defines Therapy by Repeating Phrases of Positive Thoughts (TRPPT) as the practice of mind affirmatively for positive phrases, and as protective-therapeutic factors and psychoeducation characteristics that can improve an individual's response to stress and serious mental illness, enhance coping strategies and protective factors and decreases ymptomatology, and result in a positive, adaptive outcome.

TRPPT consists of several components and techniques (ECBENP):

1. Educational Techniques (E): 1. Positive Psychoeducation (PPE). 2. States of Mind (SOM). 3. Reformation the Phrases (RP) and Positive Self-Talk (PST).

2. Cognitive Techniques (C): 1 . Technique of SelfMonitoring (TSM) and Negative Thought Stopping (NTS). 2. Positive Cognitive Restructuring (PCR). 3. Positive SelfDialogue Silent or Public (PSD-S-P) and Reorganization of Self-Talk (RST). 4. Positive Cognitive Coping Skills (PCCS).

3. Behavioral Techniques (B): 1. Relaxation, Breathing Abdominal with Repeating Phrases of Positive Thoughts (R-PT). 2. Smile or Laughter with Repeating Phrases of Positive Thoughts (S-L-PT). 3. Positive Coping Skills with people (PCS). 4. Home Work (HW).

4. Emotion Techniques (E): 1. Positive emotions related with S-L- PT. 2. Emotional development, and negative emotions liberation.

5. NeuroPsychological Techniques (NP): 1. cognitive activity related with Positive Thoughts and large volume of gray matter in Brain.

\section{Services provided by the therapeutic program}

When this program applied, it provides Educational, Development, Therapeutic, Preventive, and Cerebral Stimulation services (ETPCSD):

1. Educational services (E): TRPPT improves the States of Mind (SOM), stops Negative Rethinking and Rumination (NRR), and learns Positive Rethinking and 
Rumination (PRR), by PPE and PSD-S-P. TRPPT aims to teach the individual to be a therapist for himself and to teach the individual the ability to manage his emotions and provide him with the necessary skills to prevent the return of the disease after the improvement (prevention of relapse).

2. Therapeutic services (T): TRPPT helps the adultsto decrease the MDE, PTSD, and overthinking, and improving sleep during Wartime by TSM and NTS; PCR and PSD-S-P. TRPPT, is an educational treatment, helps to learn a more positive and efficient way of life in dealing with future difficulties where it is interested from the beginning to modify the automatic and irrational thoughts and the replacement by positive and logical thoughts contribute to the extent of individual compatibility.

3. Preventive services ( $\mathbf{P})$ : TRPPT helps the children and adolescents to avoid the problems by R-PT, S-L-PT, CS, HW, PSD-S-P.

4. Cerebral Stimulation services (CS): TRPPT strengthens brain activity (activity in the prefrontal and temporal cortices; activity in left dorsolateral prefrontal cortex; hypoactivity in right superior temporal gyrus). TRPPT improves cognitive abilities and executive functions and increases volume of gray matter (prefrontal cortex and the hippocampus). TRPPT may delays the effects of brain aging and had a benefit on the amygdala, the cerebral neuro-plasticity.

5. Development services (D): TRPPT provides developmental learning services related to the development of mental abilities and processes responsible for school-academic compatibility and personal, social and professional compatibility.

\section{Instrument and measures}

\section{Socio-demographic Data Scale}

Data on socio-demographic such as age, gender, family monthly income (economic situation), residential status, education level, and social relationships were obtained to control its impact on the variables and the results of the study taking into account the recommendation of Skelly et al., 2012, and Alsaleh, 2016a.

\section{Automatic Thoughts Questionnaire - Arabic (ATQ-18-Ar)}

The Syrian version of the ATQ-18-Ar includes 8 items on negative automatic thoughts (NAT) and 10 items on positive automatic thoughts (PAT) (Alsaleh, 2016b; Alsaleh\&Kubitary, 2016a; 2016b; 2016c). The states of mind (SOM) ratio [positive thoughts/(negative thoughts+positive thoughts)] is perhaps the best predictor of psychological well-being and mental health (see Alsaleh et al., 2015).For the current sample (Children and Adolescents), the Cronbach alpha coefficient is 0.795 [95\% Cl: $0.649-0.874]$ for the PAT score. The Split-Half (odd-even) correlation is 0.805 ( $p<$ 0.0001 ) and the Spearman-Brown Prophecy coefficient is $0.892(p<0.0001)$. The Cronbach alpha coefficient is 0.773 [95\% Cl: 0.668-0.839] for the NAT score. The Split-Half (odd-even) correlation is 0.806 ( $p<0.0001$ ) and the Spearman-Brown Prophecy coefficient is 0.893 $(p<0.0001)$.

\section{Davidson Trauma Scale (DTS)}

Each item corresponds to a DSM-IV ${ }^{T M}$ symptom of PTSD to facilitate diagnosis.

The DTS is a 17-item that assesses the 17 DSM-IV symptoms of PTSD (Davidson, Book, \&Colket, 1995; Davidson, Book, Colket, Tupler, Roth, David, Hertzberg, Mellman, Beckham, Smith, Davison, Katz, \& Feldman, 1997; Davidson, Tharwani, \& Connor, 2002).In our research, the DTS was used because the DTS was based in the diagnosis DSM-IV where each item agreed with DSM-IV ${ }^{\mathrm{TM}}$ symptom of PTSD to ease the diagnosis of trauma, was translated to Arabic by Abdul Aziz Thabet, and was used with the sample of the sons martyrs in adolescence in area of Jablah in Syria (Sady\&Badr, 2015). In the study of Sady\&Badr (2015), the Cronbach alpha coefficient was 0.762.

"The Davidson Trauma Scale (DTS) was developed as a self-rating for use in diagnosing and measuring symptom severity and treatment outcome in post-traumatic stress disorder (PTSD). The results further affirm the utility of the DTS as a self-rating measure of PTSD symptom severity and in evaluating treatment response."(Davidson et al., 2002). The DTS provides a quick and accurate measure of PTSD symptoms and assesses their frequency and severity in 
three clusters: intrusion, avoidance, and hyperarousal (Davidson et al., 1997; Samuels-Dennis, Ford-Gilboe, \& Ray, 2011).

"The DTS is a 17-item, self-rating scale that can be used to screen clients at the initial evaluation, evaluate psychopathology in trauma victims, assess the effectiveness of treatment, and predict treatment success. The scale covers all types of trauma: accident, combat, sexual or criminal assault, natural disaster, torture, burns, loss of property, near death experiences, and bereavement." (Creative Organizational Design, 2017; MHS, 2017; see also Samuels-Dennis et al., 2011).

"It can be used to make a preliminary determination about whether the symptoms meet DSM criteria for PTSD. Scores can also be calculated for each of the 3 PTSD symptom clusters (i.e., $B, C$, and D).Items are rated on 5 -point frequency $(0=$ "not at all" to $4=$ "every day") and severity scales ( 0 = "not at all distressing" to 4 = "extremely distressing"). Respondents are asked to identify the trauma that is most disturbing to them and to rate, in the past week, how much trouble they have had with each symptom." (National Center for PTSD, 2016; see also SamuelsDenniset al., 2011).

\section{Sleep Disorders Scale (SDS)}

The SDS is a 27-items self-report measure that assesses the Sleep Disorders (SD), among in the male and female students of the preparatory stage, scientific and literary for the classes (fourth, fifth, and sixth), and in the urban and rural. The Test-Retest Reliability was 0.82 (see Khadhim, 2014).

In our research, the SDS was used because there is no scale to measure sleep disorders validated in Arabic except the SDS which was developed and validated in Arabic by Khadhim (2014), and was used with the sample of the children and adolescents in Iraq (Khadhim, 2014).

\section{Kubitary-AlsalehWar Experiences Scale (KAWES)}

The KAWES was developed by Kubitary, and Alsaleh, during Wartime to assess spontaneous self-statements about the War and their experiences. The KAWES is a 19-items self-report measure that assesses the brutal and terrifying experiences, intense or traumatic experiences, direct and indirect experience, and symptoms of War experiences as fear. KAWES examines these experiences caused by war.

Items are rated on 5-point frequency ( 1 = "not at all" to 5 = "every day") and severity scales ( $1=$ "War experiences is not at all distressing" to $5=$ "War experiences is extremely distressing"). The KAWES yields a frequency score (ranging from 1 to 115) and severity score (ranging from 1 to 115). Respondents are asked to identify the experience that is most disturbing to them and to rate during Wartime.

The 19-items examine the experience of combat exposure, experience of the threat or humiliation exposure, experience of sexual harassment, experience of the horror of wars either first hand or through some of their loved ones, personal experiences related to the war, traumatic events related to the war horrible experiences. Regarding the internal consistency of the KAWES, the Cronbach alpha coefficient is 0.849 [95\% Cl: $0.754-0.899$ ] for the KAWES score. The Split-Half (odd-even) correlation is $0.679(p<0.0001)$ and the SpearmanBrown Prophecy coefficient is 0.809 ( $p<0.0001)$. The Arabic version of the KAWES is available from the first author or corresponding author (Correspondence).

\section{Statistical analysis}

Statistical analysis was performed on 41 participants (pupils at school) for the experimental group following the TRPPT. The objective of the statistical analysis is to describe and assess changes in PTSD, WE, and SD associated with repeating phrases positive thoughts (RPPT). To evaluate the effectiveness of this procedure, a comparison of scores before and after ( $\mathrm{T} 1$ vs $\mathrm{T} 2$ ) was performed for three scales (DTS, KAWES and SDS), using a test of mean comparison (Student's t-test), considering the scale of KAWES as the main variable. Shapiro-Wilk Normality Test was used with the first dataset (T1) for justify the use of t-test. The effect size, using the coefficient " $d$ " of Cohen's between T1 and T2 were calculated (Guéguen, 2009, Alsaleh, 2016b, Alsaleh\& Ventura, 2016). The threshold of significance tests is 0.05 . All statistical analysis was performed using R (programming 
language which is a free software environment for statistical computing and graphics).

\section{Study Findings during Wartime}

\section{Descriptive Statistics and Characteristics of the Sample}

Means (M), standard deviations (SD), and percent (\%) of the six variables measured in this study (number of pupils $n=41$ ) were described. The demographic characteristics of participants are presented in Table 1. The various correlation coefficients between the variables used in the study are reported in Table 2 . Negative thoughts were inversely correlated with positive thoughts. PTSD was significantly correlated with WE and SD.

Table 1. Analysis Descriptive Statistics: Characteristics of the Samples.

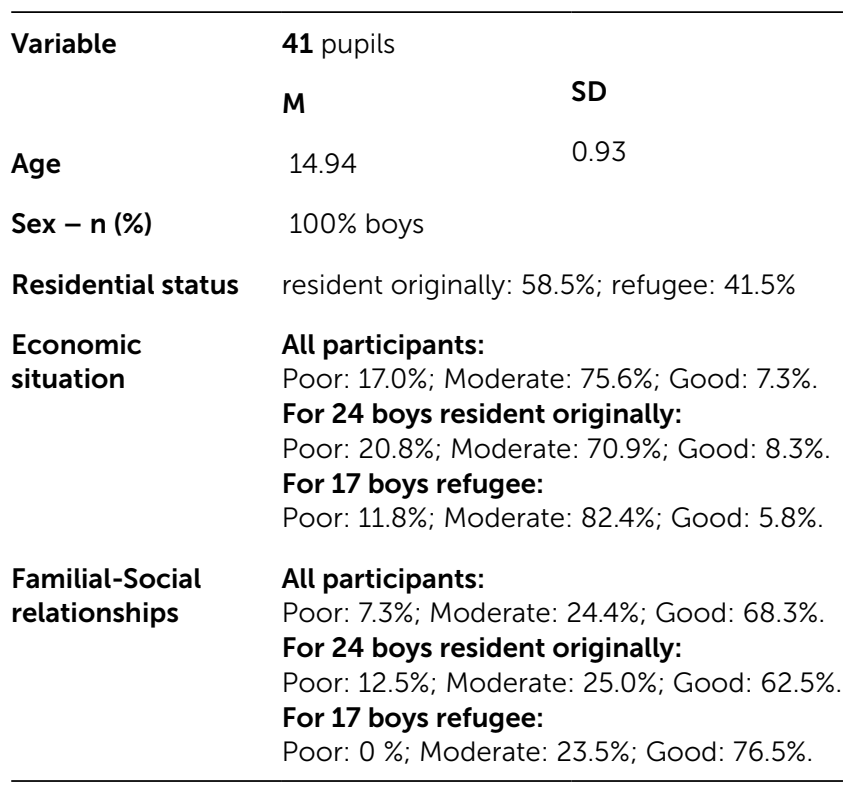

Table 2. Bivariate Correlations among Variables

\begin{tabular}{|c|c|c|c|c|c|c|}
\hline & NAT & PAT & SOM & PTSD & SD & WE \\
\hline NAT & 1.00 & $-0.32 *$ & * $-0.82^{* * *}$ & $0.65^{* * *}$ & $0.39 * *$ & 0.08 \\
\hline PAT & & 1.00 & $0.78^{* * *}$ & * $-0.42^{* *}$ & $-0.33^{*}$ & $-0.14 *$ \\
\hline SOM & & & 1.00 & $-0.65^{* * *}$ & $-0.41^{*}$ & $-0.17^{*}$ \\
\hline PTSD & & & & 1.00 & 0.58 ** & $0.31^{*}$ \\
\hline SD & & & & & 1.00 & $0.23^{*}$ \\
\hline WE & & & & & & 1.00 \\
\hline
\end{tabular}

Note: ${ }^{\star} p<0.05\left(2\right.$-tailed) ${ }^{* *} p<0.01(2$-tailed):*** $p<0.001$ (2-tailed).

\section{Construct Validity}

Construct Validity (Convergent and Divergent Validity) for DTS, SDS, and KAWES was tested using $r$ Pearson's correlations. Table 2 shows the inter-correlations between the scales. The correlations confirm the convergent and divergent validity of the DTS, the SDS, and the KAWES (see Table 2). Therefore, the DTS, the SDS, and the KAWES show good construct validity (convergent and divergent validity). DTS, SDS, and KAWES also show good external validity of structure.

\section{Confounding factors and their impacts on TRPPT}

According to recommendation of Skelly et al., 2012, and Alsaleh, 2016a, during study planning and analysis, confounding factors such as socio-demographic-economic factors must be examined and association between these factors and the outcome must be explored.

For that, a multiple regression and a multivariate analysis have been performed on the first (T1) and second (T2) dataset in order to evaluate the role of confounding factors on final results, especially gender, age, residential status, economic situation and familialsocial relationships.

In order to avoid if sex and education level have an effect on the TRPPT, the study only takes the boys; and a single level of education was selected to control its effect on variables and outcomes which is a middle school, especially the ninth grade.

According to regressions analysis, t-student and ANOVA, age, residential status, economic situation and familial-social relationships have no influence $(p>0.05)$ on PTSD in first dataset (T1) before the TRPPT and second dataset (T2) after the TRPPT (Table 3).Concerning age of the participants, their economic situation, t-student and ANOVA indicate significant effect on SD $(p<0.05)$ in first dataset (T1), but after the TRPPT (T2)age of the participants, their economic situation have no significant effect on SD ( $p>0.05)$. Their residential status, and familialsocial relationships have no significant effect on $S D(p>0.05)$ in T1 and T2.Residential status had a significant effect on WE $(p<0.05)$ in first dataset (T1), but after the TRPPT (T2) their residential status had no significant effect on WE 
( $p>0.05)$. The age of the participants, their economic situation and familial-social relationships have no significant effect on WE ( $p>0.05)$ in T1 and T2 (see Table 3).

It appears, according to these results, that these five variables have no influence on the components of WE, PTSD and SD after the TRPPT (T2) in comparing with before the TRPPT (T1).

\section{Thinking, TRPPT, PTSD, WE, and SD}

Shapiro-Wilk Normality Test in T1 returns a non- significant $p$-value $(p>0.05)$ for the three variables (PTSD, WE, and SD). The sample thus follows a normal distribution.

The TRPPT had a positive effect on the pupils. They have a diminished PTSD, WE, and SD between the beginning and end of the treatment (Table 4). There is a significant reduction in PTSD, WE, and SD following the TRPPT protocol. The RPPT, thus, significantly reduce DTS $(p<0.05)$, WE $(p<0.01)$, and SD $(p<0.001)$.

Table 3. Multivariate analysis for dealing with confounding.

\begin{tabular}{|c|c|c|c|c|c|c|c|c|}
\hline & $\begin{array}{l}\text { WE } \\
\text { (T1) }\end{array}$ & $\begin{array}{l}\text { PTSD } \\
\text { (T1) }\end{array}$ & $\begin{array}{l}\text { SD } \\
\text { (T1) }\end{array}$ & $\begin{array}{l}\text { NE } \\
\text { (T1) }\end{array}$ & $\begin{array}{l}\text { WE } \\
\text { (T2) }\end{array}$ & $\begin{array}{l}\text { PTSD } \\
\text { (T2) }\end{array}$ & $\begin{array}{l}\text { SD } \\
\text { (T2) }\end{array}$ & $\begin{array}{l}\mathrm{NE} \\
\text { (T2) }\end{array}$ \\
\hline Gender & I & I & I & I & I & I & I & I \\
\hline $\begin{array}{l}\text { Education } \\
\text { level }\end{array}$ & / & I & I & I & I & I & I & I \\
\hline Age & $p>0.05$ & $p>0.05$ & $\begin{array}{l}p<0.05 \\
13-14 \text { years }= \\
55.92 \\
15-17 \text { years }= \\
64.32\end{array}$ & $p>0.05$ & $p>0.05$ & $p>0.05$ & $\begin{array}{l}p>0.05 \\
13-14 \text { years }= \\
36.1 ; \\
15-17 \text { years }= \\
34.4\end{array}$ & $p>0.05$ \\
\hline $\begin{array}{l}\text { Residential } \\
\text { status }\end{array}$ & $\begin{array}{l}p<0.05 \\
\text { living = 51.42; } \\
\text { refugee }=61.29\end{array}$ & $p>0.05$ & $p>0.05$ & $p>0.05$ & $\begin{array}{l}p>0.05 \\
\text { living }=46.9 ; \\
\text { refugee }=45.2\end{array}$ & $p>0.05$ & $p>0.05$ & $p>0.05$ \\
\hline $\begin{array}{l}\text { Economic } \\
\text { situation }\end{array}$ & $p>0.05$ & $p>0.05$ & $\begin{array}{l}p>0.05 \\
\text { Poor }=52.0 \\
\text { Moderate }=63.4 \\
\text { Good }=66.7\end{array}$ & $p>0.05$ & $p>0.05$ & $p>0.05$ & $\begin{array}{l}p>0.05 \\
\text { Poor }=33.6 \\
\text { Moderate }=34.2 \\
\text { Good }=45.7\end{array}$ & $p>0.05$ \\
\hline $\begin{array}{l}\text { Familial-social } \\
\text { relationships }\end{array}$ & $p>0.05$ & $p>0.05$ & $p>0.05$ & $p>0.05$ & $p>0.05$ & $p>0.05$ & $p>0.05$ & $p>0.05$ \\
\hline
\end{tabular}

It contains only the most important results for this study.

Note: ${ }^{*} p<0.05$ ( 2 -tailed); ${ }^{* *} p<0.01$ ( 2 -tailed); ${ }^{* \star} p<0.001$ ( 2 -tailed). $\mathrm{p} p>0.05$ ( 2 -tailed).

Table 4. Effect of TRPPT on DTS, KAWES and SDS

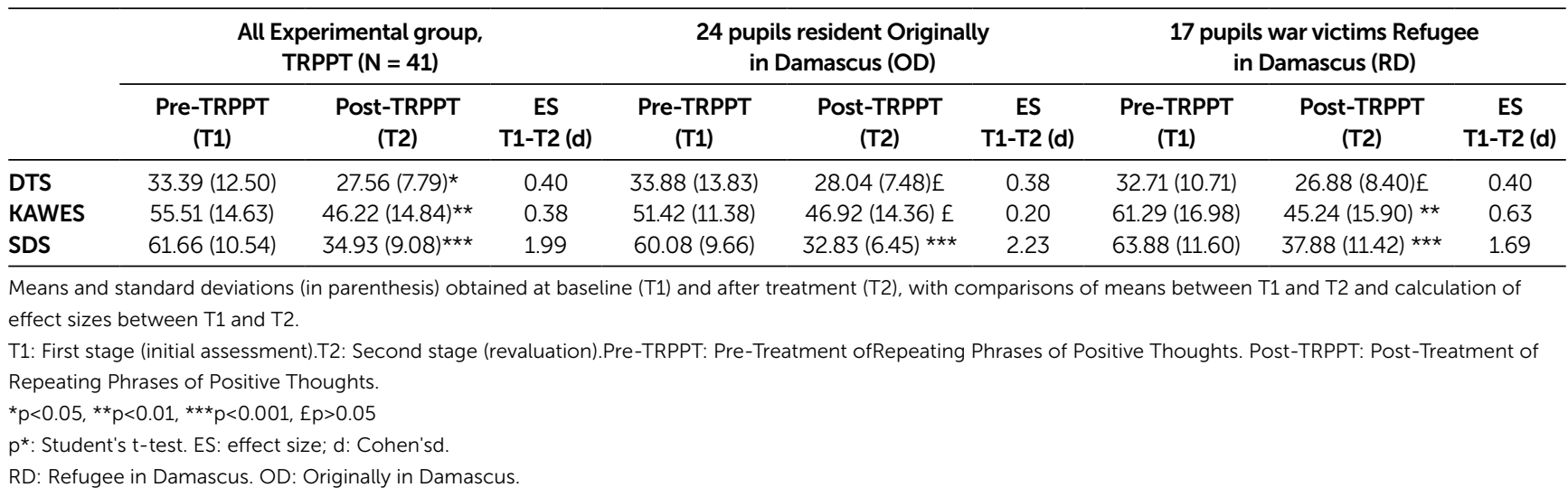




\section{TRPPT and PTSD}

PTSD was significantly correlated with SOM ratios, negative thinking, and positive thinking in descending order of magnitude (see Table2). Effect size (ES) showed that TRPPT $(p<0.05)$ significantly affect PTSD (see Table 4).

\section{TRPPT and WE}

WEwere significantly correlated with SOM ratios, and positive thinking in descending order of magnitude. Negative thinking was not significantly correlated with WE (see Table2). ES showed that TRPPT $(p<0.01)$ significantly affect WE (see Table 4).

\section{TRPPT and SD}

SD was significantly correlated with SOM ratios, negative thinking, and positive thinking in descending order of magnitude (see Table2). ES showed that TRPPT $(p<0.001)$ significantly affect SD (see Table 4$)$.

\section{DISCUSSION}

This research aimed to study the effects of the TRPPT on Syrian children ascents subjected to WE, very few people solicited so far in the literature. People during wartime have worries about their future. Mental health problems are very common among Syrian (refugees or non-refugees). Posttraumatic Stress Disorder (PTSD), Sleep Disorder (SD) and War Experiences (WE) are one of the most common mental disorders among Syrian. The results of this research show effectiveness of TRPPT on the PTSD, WE, and SD. There are few studies on the effects of Cognitive and Positive psychotherapy (CPPT) Syrian children and adolescents in primary education settings, specifically in schools in the Syrian interior during Wartime, despite the potential beneficial effects on states of mind and psychological.

This study used one group of 41 Syrian children and adolescents, ages 13 to 17 from a school in Damascus during Wartime. The experimental group participated in 5-weeks (33 days). Daily TRPPT program which trained their attention to automatic thought (negative automatic thought and positive automatic thought), to the impact of automatic though on senses, body, sleep, brain, and family and social relationships. Following the intervention, the
TRPPT group improved the PTSD, WE, and SD. These results show that TRPPT in a War setting and schools settings is feasible and produces beneficial results in the short term. The need for psychotherapy in front-line health care is considerable, but individual treatment is costly. Participants aged 13 to 17 years were randomized to receive group therapy, lasting 5 weeks, having lived and live direct and indirect War experiences during Wartime in Syria. Only in refugees group, War experiences improved in children and adolescents who have lived direct War experiences. In both groups, sleep improved similarly.

\section{Effects on sleep disorders}

A single night of sleep deprivation alters the optimal functioning of the response to negative and unpleasant events (Goldstein et al., 2013). An increase in activity in deep emotional areas, especially in the amygdala region, was observed. Sleep seems to restore the circuits of emotions and thus prepare for tomorrow's challenges and social interactions. Without sleep, the brain regressed to a more primitive level of activity, becoming incapable of putting emotional experiences into context and producing appropriate responses (Goldstein et al., 2013). Lack of sleep is associated with worse food choices (American Academy of Sleep Medicine, 2012). During bombing events, children suffer from sleep problems (see Dhamrah\&Abueita, 2014). During Wartime, children and adolescents also suffer from sleep disorders. Five weeks of daily cognitive and positive training significantly decreased sleep disorders levels in Syrian children and adolescents between the ages of 13 and 17. Syrian refugees' children and adolescents who suffer from War Experiences are disadvantaged populations from a good sleep and quality sleep. The results of this study confirm similar positive effects found in these disadvantaged populations from a good sleep and populations do not suffer direct War Experiences as children and adolescents resident originally in Damascus. These results lead us to believe that good sleep by CPPT training and TRPPT improve and increase in activity in deep brain regions governing emotions.

Lack of sleep affects the brain areas involved in the regulation of emotions, greatly increasing the tendency to 
anxiety (Goldstein et al., 2013). The Syrians, after nights of sleep deprivation during 7 years of wartime, negative experiences were anticipated and psychiatric disorders. In this study, sleep improved and SD reduced.

\section{Effects on war experiences and posttraumatic stress disorder}

TRPPT effects on PTSD and WE were important, but less clear that SD. DTS is considered a measure of PTSD and DSM-IV symptoms of PTSD (Davidson et al., 1995, 1997, 2002), so TRPPT was seen to reduce PTSD and symptoms. The separate analysis of the subsample (24 pupils resident originally in Damascus, 17 pupils war victims refugee in Damascus) show that scores means of PTSD reduced. The separate analysis of the subsample show the effects were only positive in the WE in pupils war victims refugee. These Syrian children and adolescents suffer from direct War experiences. However, Syrian children and adolescents resident originally in Damascus do not suffer the direct War experiences.

\section{Positive feedback on TRPPT}

"Hunter \& Csikszentmihalyi (2003) add that "depression makes the world dull, gray, and lifeless." (Cited in Kirkegaard-Weston, 2005). Children are increasingly being prescribed psychotropic drugs (Easterbrook 2001), and to me, that is an extremely scary concept (cited in KirkegaardWeston, 2005). Because doctors are willing to prescribe drugs for children with "mental disorders" at a higher rate than ever before, that means that either parents have tried other non-prescriptive drug methods to instill more joy in the lives of children and those haven't worked, or the parents haven't tried any other remedies and are looking for a quick medical fix. Neither one of those scenarios are healthy, and if our young generations are taught that medicine will make them happy, I am sad to say that the outlook of our future generations doesn't look so positive. Children are the future of the world; but positive thinking is not things usually on an adolescents' mind. Mentors, teachers, and ohana can all lead change in youth by first, practicing positive thinking and being optimists, and then guiding youth to follow the path they have already laid" (see Kirkegaard-Weston, 2005).
School director, school management team, teaching staff, families of pupils, pupils produced positive changes and showed positive feedback and a high level of acceptance of the TRPPT program. During the training period and during 5 weeks with TRPPT program, children and adolescents felt increased wellbeing, joy, calmness, positive emotions, peace of mind and relaxation, they said them. Positive feedback on this program in school leads us to suggest that cognitive and positive training must be conducted beginning of each academic year and/or all through the school year. Positive feedbacks on this program in family push us to the proposal that cognitive and positive training must be carried out with families and especially parents. These positive feedbacks lead us to believe that TRPPT, their techniques and cognitive and positive training are useful tool that could be utilized with Syrian children and adolescents and refugees' children and adolescents, in national and international educational programs for children and adolescents, educational environment, family and social environment.

TRPPT cannot be limited to one-week and/or fiveweek training. Systematic, perseverance, continued practice of TRPPT each day (morning and evening and in the heart of the day) and over long periods of time are a basic principle of its effectiveness against mental illness and improve the mental health and wellbeing.

\section{Personalized TRPPT help Syrian children and adolescents with direct and indirect War Experiences}

Many experts and advocates of patients call for reducing the use of antipsychotic and anxiolytic drugs (Thomas, Baier, Kosar, Ogarek, Trepman, \&Mor, 2017). Personalized or non-personalized TRPPT are beneficial to people experiencing direct and indirect warfare and other negative experiences.

These results lead us to believe that the participants who implemented the program were much more likely to stop the drugs as anti-stress, antidepressant and anxiolytic drugs if they take them. We observed also reductions in disruptive behavior, behavior improvement and improvement in mood. Participants who implemented 
the program were much more likely to decrease PTSD and SD symptoms, more likely to improve in mood, and much less likely to have disruptive and antisocial behavior, according to the first evaluation of the program with children and adolescents during Wartime. Behavioral improvements are not only beneficial for the individual pupils, but also enhance and improve the quality of life for other pupils around them, and the morale of teachers in school and families in home. This is promising. It's a first step to understanding that there are improvements in WE, PTSD and SD that can be attributed to this intervention.

Providers and caregivers are looking for nonpharmacological interventions to address behaviors (Thomas et al., 2017). "A mentor can also play an important role in a child's life by using positive self-phrases in everyday life" (Kirkegaard-Weston, 2005; see also Alsaleh, 2016a, 2016b; Alsaleh\&Kubitary, 2017).Without a doubt, teachers in school and families in home always are looking for interventions and methods to address behaviors children and adolescents either in school or in the home. When we give the Phrases of Positive Thoughts for pupils in school, their lips laughed, their breathing relaxed, their sad face smiled, and their grimaced face relaxed. In other words, the TRPPT program may have an even greater impact than reported.

TRPPT and cognitive and positive training have effects on sleep disorders and war experiences, but insufficient effect on posttraumatic stress disorder. Perhaps longer training periods on cognitive and positive training would be needed to produce significant effects on posttraumatic stress disorder. Despite this limitation, parents did notice a positive immediate effect on their children and their adolescent at the home. Future research should verify these effects. To improve our evaluation and study, we plan to conduct a second study in taking account for the current limitations.

The main weakness is the methodological limitation of this study is that there is no control group. It is possible of take the control group, but there are three reasons which we push for no take the control group: 1. To benefit the largest possible number of pupils from therapeutic psychological program during Wartime; 2. Beyond T2, participations in the control group can be ask if they wish join the experimental group after T2 according to the same modalities as the experimental group. But to gain time and because of practical and logistical difficulties during Wartime, all participants include in the experimental group; 3. In studies of Alsaleh with clinical and non-clinical samples, experimental group who benefited from treatment have lower level of depression, anxiety and stress compared with control groups. Negative automatic thought, negativity affectivity, depression, anxiety, stress decrease after Therapy by Repeating Phrases of Positive Thoughts; and positive automatic thought, positive affectivity, self-esteem and satisfaction in life improve among patients with multiple sclerosis (MS) and students after Therapy by Repeating Phrases of Positive Thoughts (Alsaleh, 2016a, 2016b; Alsaleh\&Kubitary, 2016a, 2016b, 2016c; Alsaleh, et al., 2017; Alsaleh\&Kubitary, 2017). Future researches can be taking the control group during peacetime. It is interesting to reuse and reexamine the role of TRPPT in a rural primary school and its effects on attention, memory, concentration, revision for the exams and performance and school achievement during the lesson. There are few studies on the effects of psychotherapy (PT) in education settings, specifically in rural schools and primary education settings. For future researches, it would be interesting, if possible, to examine the impact of other factors, such as number of children, order of the child in the family, single child for example. We wanted to measure the impact TRPPT on PTSD, WE, and SD during the treatment and during the follow-up of the treatment after one month and more, but because of practical and logistical difficulties during Wartime, we have fixed our attention on $\mathrm{T} 1$ and $\mathrm{T} 2$. Future researches can measure the impact TRPPT during the treatment and during the follow-up.

Consequently, the effects of TRPPT during Wartime and in a school setting are very important. It is must be monitored in longitudinal studies which last several years in normal conditions. Our findings support the feasibility of the use of Cognitive and Positive psychotherapy (CPPT) basing on the Treatment by Repeating Phrases of Positive Thoughts (TRPPT) as an enrichment strategy during Wartime in home and school settings. This feasibility 
during Wartime is reinforced by the positive perception of the training among Syrian children and adolescents in the school community and family community.

\section{Conflict of interest}

The author declares that there are no conflicts of interest with respect to this study or its publication.

\section{References}

Acarturk, C., Konuk, E., Cetinkaya, M., Senay, I., Sijbrandij, M., Cuijpers, P., \& Aker, T. (2015). EMDR for Syrian refugees with post-traumatic stress disorder symptoms: results of a pilot randomized controlled trial. European Journal of Psychotraumatology, 6, 27414.

AL-Balhan, E. (2006). The Children's Depression Inventory as a reliable measure for post-Iraqi invasion Kuwaiti youth. The journal of social behavior and personality, 34 (2): 351-366.

Alsaleh, M. (2016a). Therapy mental and psychological troubles (MPSYT) by Repeating Phrases of Positive Thoughts (TRPPT) with Women.Intercultural Comparison: Middle East and Europe, war and peace.A controlled and randomized studyCognitive therapy \& Positive psychotherapy.Journal of Psychology and Cognition; 1 (1): 70-80.

Alsaleh, M. (2016b). Analyse psychosociale et cognitive de la santé mentale chez les étudiants de première année: - Validation du questionnaire des pensées positives et négatives et $d u$ questionnaire de la dépression de Beck; - Effet des pensées positives et des facteurs psychosociaux. Thèse- Ecole Doctorale 556-CERReV; Laboratoire du CERReV (EA 3918), Université de Caen Normandie.

Alsaleh, M., \& Ventura, A. (2016). Validation des questionnaires d'évaluation en psychologie: comment apprécier correctement leurs qualités psychométriques et métrologiques?Éditions universitaires européennes.

Alsaleh, M., \& Kubitary, A. (2016a). Treatment by Repeating Phrases of Positive Thoughts (TRPPT): A new effective treatment tool against psychological troubles (PSYT) in multiple sclerosis patients and students, a controlled and randomized pilot study. Journal of Psychology and Cognition; 1 (1): 57-63.

Alsaleh, M., \& Kubitary, A. (2016b). New Frontiers in the Treatment of Mental-war Disorders and Posttraumatic Disorder by Repeating Phrases of Positive Thoughts (TRPPT) of Syrian refugees Populations War Victims: Results of a Pilot Randomized Controlled Trial. Journal of Biomedical Sciences, $6: 1$.

Alsaleh, M., \&Kubitary, A. (2016c). Validation of the Automatic Thoughts Questionnaire (ATQ-18-MS-Ar) Among Multiple Sclerosis Patients. Journal of Psychology and Cognition; 1 (1): 64-69.

Alsaleh, M., \& Kubitary, A. (2017). Verdicts of Water DropsTRPPT on brain and life New Frontiers in NeuroCognitive Positive Psychotherapy in War and Peace, Normal-Abnormal-Medicalnon-Medical Conditions. Éditions universitaires européennes.

Alsaleh, M., Lebreuilly, R., Lebreuilly, J., \&Tostain, M. (2015). Cognitive Balance: States-of-Mind Model and Mental Health among French Students. Best Practices in Mental Health: An International Journal, Vol. 11, No. 1, 42-53.

\section{Disclosure of potential conflicts of interest}

The author declares that he has no competing interest.

\section{Acknowledgments}

The author thanks all the participants in this study.

Alsaleh, M., Lebreuilly, R., Lebreuilly, J., \&Tostain, M. (2017). La puissance des Répétitions des Phrases des Pensées Positives (RPPP): Un outil efficace de traitement contre les troubles psychologiques (dépression, anxiété et stress): Une étude pilote contrôlée et randomisée. Annales Medicopsychologiques. In presse.

AL-Shagran, H., Khasawneh, O. M., Ahmed, A. K., \& Jarrah, A. M. (2015). Post-Traumatic Stress Disorder of Syrian Refugees in Jordan.International Journal of Liberal Arts and Social Science, 3 (3), 36-48.

American Academy of Sleep Medicine. (2012). MRI scans show how sleep loss affects the ability to choose proper foods. ScienceDaily. <w ww. sciencedaily.com / releases/2012/06/120610151445.htm>.

Ammar, N. H. (2006). Beyond the Shadows: Domestic Spousal violence in a -democratizing-Egypt Trauma. Violence and Abuse Journal, 7, 244-259.

Arenaza-Urquijo, E.M., de Flores, R., Gonneaud, J., Wirth, M., Ourry, V., Callewaert, W., Landeau, B., Egret, S., Mézenge, F., Desgranges, B., \& Chételat, G. (2016). Distinct effects of late adulthood cognitive and physical activities on gray matter volume. Brain Imaging and Behavior, 11 (2), 346-356.

Baddoura, C., \& Merhi, M. (2015). PTSD among Children and Adolescents in the Arab World. The Arab Journal of Psychiatry, 26, 2, $129-136$.

Belhsini, W. (2011). Effet d'un programme cognitif et comportemental dans le traitement de la phobie sociale sur un échantillon d'étudiants de l'université. Thèse, Université KasdiMerbahOuargla.

Berthold, S. M. (2000). War Traumas and Community Violence: Psychological, Behavioral, and Academic Outcomes among Khmer Refugee Adolescents. Journal of adolescent and violence, 4 (3): 15-46.

Brown, E., Pearlman, M., \& Goodman, R. (2004). Facing Fears and Sadness: Cognitive-Behavioral Therapy for Childhood Traumatic Grief. Harvard Review Psychiatry, 2(12):187-198.

Cohen, A. J. (2005). Treating Traumatized Children: Current Status and Future Directions. Acute Reactions to Trauma and Psychotherapy, 2 (5): 545-551.

Cohen, A., and Mannarino, P. (2008). Trauma-Focused Cognitive Behavioral Therapy for Children and Parents. Child and Adolescent Mental Health, 13(4):158-162.

Cohen, J. A., and Mannarino, A. P. (1998). Interventions for sexually abused children: Initial treatment findings. Child Maltreatment, 3, 17-26.

Creative Organizational Design. (2017). Davidson Trauma ScaleQuickly and accurately measure Posttraumatic Stress Disorder (PTSD) symptoms. Creative Organizational Design, Inc. http:// www.creativeorgdesign.com/tests_page. php? id=458 
Damra, J.K., \& Nassar, Y. H. (2014). The Effect of Cognitive Behavioral Trauma Focused Therapy Model on Sample of War Children's Depression Symptomatology. Department of Educational Psychology, Faculty of Educational Sciences, Hashemite University, Jordan.

Davidson, J. R. T., Book, S. W., Colket, J. T., Tupler, L. A., Roth, S., David, D., Hertzberg, M., Mellman, T., Beckham, J. C., Smith, R., Davison, R. M., Katz, R., \&Feldman, M. (1997). Assessment of a new self-rating scale for post-traumatic stress disorder. Psychological Medicine, 27, 153-160.

Davidson, J. R. T., Book, S. W.,\&Colket, J. T. (1995). Davidson SelfRating PTSD Scale. Available from Multi-Health Systems, Inc., 908 Niagara Falls Boulevard, North Tonawanda, NY 14120.

Davidson, J.R.T., Tharwani, H. M., \&Connor, K. M. (2002). Davidson Trauma Scale (DTS): Normative scores in the general population and effect sizes in placebo-controlled SSRI trials. Depression and Anxiety, 15, 75-78.

deRoos, C., Greenwald, R., den Hollander-Gijsman, M., Noorthoorn, E., van Buuren, S., \& de Jongh, A. (2011). A randomised comparison of cognitive behavioural therapy (CBT) and eye movement desensitisation and reprocessing (EMDR) in disaster-exposed children.European Journal of Psychotraumatology, 2: 5694.

Dhamrah, J., \& Abueita, S. (2014). The Effect of Trauma Focused Cognitive Behavioral Therapy and Music Therapy on decreasing the Posttraumatic Stress Symptomatology among a Sample of War Children. Department of Educational Psychology, Faculty of Sciences Education, Hashemite University, Jordan.

Eskin, M., Ertekin, K., \& Demir, H. (2008). Efficacy of a ProblemSolving Therapy for Depression and Suicide Potential in Adolescents and Young Adults. Cognitive Therapy Researches, 32(1): 227-245.

Feather.S., \& Ronan.R. (2009). Trauma-Focused CBT with maltreated children: A clinic-based evaluation of a new treatment manual. Australian Psychologist, 44, (3), 174-194.

Goldstein, A.N., Greer, S.M., Saletin, J.M., Harvey, A.G., Nitschke, J.B., \& M.P. Walker. (2013). Tired and Apprehensive: Anxiety Amplifies the Impact of Sleep Loss on Aversive Brain Anticipation. Journal of Neuroscience, 33 (26) 10607-10615.

Guéguen, N. (2009). L'importance d'un effet: Méthodologie Simple De Détermination Et D'évaluation De «L'effect Size ». European Journal of Scientific Research. 38(1), 20-25.

Hasanovic, M. (2012). Posttraumatic Stress Disorder in Bosnian Internally Displaced and Refugee Adolescents from Three Different Regions after the 1992-1995 War in Bosnia and Herzegovina," Paediatrics Today 8, no. 1,22-31.

Hase, M., Balmaceda, U.M., Hase, A., Lehnung, M., Tumani, V., Huchzermeier, C., \& Hofmann, A. (2015). Eye movement desensitization and reprocessing (EMDR) therapy in the treatment of depression: a matched pairs study in an inpatient setting. Brain and Behavior, 5(6), e00342.

Henley, J., \& Robinson, J. (2011). Mental health issues among refugee children and adolescents. Clinical Psychologist 15, no. 2, 51-62.

Hunter, J. P., \& Csikszentmihalyi, M. (2003). The Positive Psychology of Interested Adolescents.Journal of Youth and Adolescence, 32, 1, 27-35.

Khadhim, A.M. (2014). Measuring Sleep Disorders in the Students of the Preparatory Stage.University of Babylon, Journal of the Faculty of Basic Education, 15.

Kirkegaard-Weston, E. (2005). Positive Thinking: Toward a Conceptual Model and Organizational Implications. Honors College Theses. Pace University.http://digitalcommons.pace. edu/honorscollege_theses/15
Koseki, S., Noda, T., Yokoyama, S., Kunisato, Y., Ito, D., Suyama, H., Matsuda, T., Sugimura, Y., Ishihara, N., Shimizu, Y., Nakazawa, K., Yoshida, S., Arima, K., \& Suzuki, S. (2013). The relationship between positive and negative automatic thought and activity in the prefrontal and temporal cortices: A multi-channel nearinfrared spectroscopy (NIRS) study.Journal of Affective Disorders, 151, 352-359.

Kubitary A., Alomer, M., \&Alsaleh, M.A. (2017). Validity of the Arabic version of Beck Depression inventory-Fast Screen (BDI-FS-Ar) in war: The psychometric properties in medical and nonmedical Syrian populations. Nova Science Publishers, Inc. https://www.novapublishers.com/catalog/product_info. php?products_id $=62627$

Kubitary, A., \& Alsaleh, M. (2017). Validity of the Arabian version of the Quick Inventory of Depression-Two questions (QID-2-Ar) in patients with multiple sclerosis.Screening and multiple sclerosis in Arabian environment-War conditions in Syria.Revue neurologique, in presse.

MHS (MULTI-HEALTH SYSTEMS). (2017). DTSTM (Davidson Trauma Scale) - Jonathan Davidson, Psychological Assessments and Service. (MULTI-HEALTH SYSTEMS. https://ecomx.mhs.com/ ( $S($ l i 4 jww fxoq0 p 2 j 55 l 4 fdq 355 )) / product. aspx?gr=cli\&prod=dts\&id=overview\#scales

Mohlen, H., Parzer, P., Resch, F., \& Brunner, R. (2005). Psychosocial Support for War-Traumatized Child and Adolescent refugees: Evaluation of a short-term treatment program. Australian and New Zealand Journal of Psychiatry, 39 (3): 81-87.

National Center for PTSD. (2016). Davidson Trauma Scale (DTS), Davidson, 1997. Mental Health Systems.Inc. U.S. Department of Veterans Affairs- Washington.https://www.ptsd.va.gov/ professional/assessment/adult-sr/dts.asp

Oras, R., De Ezpeleta, S. C., \& Ahmad, A. (2004). Treatment of Traumatized Refugee Children, with Eye Movement Desensitization and Reprocessing in a psychodynamic context. Nord Journal Psychiatry, 58(3): 199-203.

Papageorgiou, V., Frangou-Garunovic, A., Iordanidou, R., Yule, W., Smith, P., \& Vostanis, P. (2000). War Trauma and Psychopathology in Bosnian refugee children. European Child and Adolescent Psychiatry, 9 (6): 84-90.

Raider, M. C., Steele, W., Delillo-Storey, M., Jacobs, J., \& Kuban, C. (2008).Structured Sensory Therapy (SITCAP-ART) for Traumatized Adjudicated Adolescents in Residential Treatment.Residential Treatment for Children and Youth, 25 (2): 167-185.

Ricarte, J. J., Ros, L., \& Latorre, J. M. (2015). Mindfulness-Based Intervention in a Rural Primary School: Effects on Attention, Concentration and Mood.International Journal of Cognitive Therapy, 8, 1-11.

Sady, R., \& Badr, E. (2015). The level of Post-Traumatic Stress Disorder (PTSD). Field Study on a sample of the sons martyrs in adolescence in area of Jablah. Tishreen University Journal for Research and Scientific Studies - Arts and Humanities Series, 37,5. 265- 280

Samuels-Dennis, J.A., Ford-Gilboe, M., \& Ray, S. (2011). Single Mother's Adverse and Traumatic Experiences and PostTraumatic Stress Symptoms. Journal of Family ViolenceNursing Publications, Western University, 26,1, 9-20.

Sirin, S. R., \& Rogers-Sirin, L. (2015). The Educational and Mental Health Needs of Syrian Refugee Children. Washington, DC: Migration Policy Institute.

Skelly, A.C., Dettori, J. R., \& Brodt, E. D. (2012). Assessing bias: the importance of considering confounding. Evidence-Based Spine-Care Journal, 3 (1), 9-12. 
Thabet, A.A. M., Abed, Y., \& Vostanis, P. (2004). Comorbidity of PTSD and Depression among Refugee Children during War Conflict," Journal of Child Psychology and Psychiatry 45, no. 3, $533-42$.

Thomas, K.S., Baier, R., Kosar, C., Ogarek, J., Trepman, A., \& Mor, V. (2017). Individualized Music Program is Associated with Improved Outcomes for U.S. Nursing Home Residents with Dementia. The American Journal of Geriatric Psychiatry, In Press.

United Nations High Commissioner for Refugees (UNHCR). (2004). Statistical yearbook. Geneva, Switzerland: United Nations.
United Nations High Commissioner for Refugees (UNHCR). (2013a). Displacement. The new 21st century challenge global trends 2012. Geneva, Switzerland: United Nations.

Vernberg, E. (2002). Intervention approaches following disasters. In A. M. LaGreca, W. K. Silverman, E. M. Vernberg, and M. C. Roberts (Eds), Helping children Cope with disasters and terrorism (P.55-72). Washington, DC: American Psychological Association.

Zauszniewski, J. A., Bekhet, A.K., \& Jane Suresky, M. (2009). Effects on Resilience of Women Family Caregivers of Adults With Serious Mental Illness: The Role of Positive Cognitions. Archives of Psychiatric Nursing, 23, 6, 412-422. 